\title{
THE IMPACT OF THE ELEVATOR GUIDES CONTAMINATION ON THE BRAKING PROCESS DELAY FOR SELECTED PROGRESSIVE GEARS
}

\author{
Rafał Longwic ${ }^{1}, K^{\prime}$ amil Szydło ${ }^{1}$ \\ 1 University of Technology, Department of Automotive Vehicles, Nadbystrzycka Street 36, 20-618 Lublin, \\ e-mail: r.longwic@pollub.pl, kamil-szydlo@wp.pl
}

Received: 2016.10 .18

Accepted: 2017.02.09

Published: 2017.06.01

\begin{abstract}
The authors' tests results on the impact of the guiding system (the guides) contamination in the friction lift on the delay of progressive gears braking process are presented in this article. The tests were conducted using a free fall method and a test bench built for that purpose. In order to render all working conditions the guiding system of tested gears was lubricated with the most commonly used lubricating agents. Solid grease (SM), mineral oil (OL), the mixture of solid grease and quartz sand (S50) as well as the mixture of mineral oil and quartz sand (O50) were used.
\end{abstract}

Keywords: elevator, progressive gears.

\section{INTRODUCTION}

When the friction lifts are operated they move along the steel guides which are usually placed in the concrete shafts. The guides play a role of a guiding system for the cabin [3] in motion. The gears (brakes) are installed under each cabin. The gears operation depends on the nominal speed of a lifting device. The lift guide (Fig. 1) consists of a mounting part and a guiding one. When the gears are operated the guides are subject to overloading. That is why two different types of the guides are manufactured. The drawn and the ground guides are used. The lift guide is presented in a schematic way in the Figure 1. The main variable dimensions depending on the type of the lifting device and the main parts of the guide are illustrated in the Figure 1. During the lifts service life the guides can be dry or lubricated with a lubricating agent as per lifts manufacturer's instructions. Solid greases or mineral oils can be used as lubricating agents. Due to the nature of the lifting device operation, there is huge dustiness in the lifts shafts. The dust settles on the guides. It has a negative impact on the guide cooperation with the guide shoes. Consequently, the comfort of the guide shoe moving along the guide is re- duced (the noise increases). Contamination on the guides can disturb the braking process and in consequence [5]:

- the carrying ties can break off,

- there can be a failure of power plant causing a rapid acceleration of the cabin.

In the articles $[1,2]$ the authors paid their attention to the application of different types of polymer. The polymer was used as an envelope of the roller in the lift guide shoe. The authors' tests results, focused on the dimensional repeatability of the roller envelope in changing loading, were presented in the study. The results of numerical analysis and verification of received results for CHP 2000 type progressive gear conducted on the test bench are presented by the authors in the research study [4]. The results of numerical calculations obtained by the authors were in line with the results of experimental tests. Four types of progressive gears available in the market are described and compared in the article [5] in respect of the new construction of CHP 2000 type gear. The received results of calculations for the braking process delay, free movement of a braking roller and the gears kinematics allowed the au- 


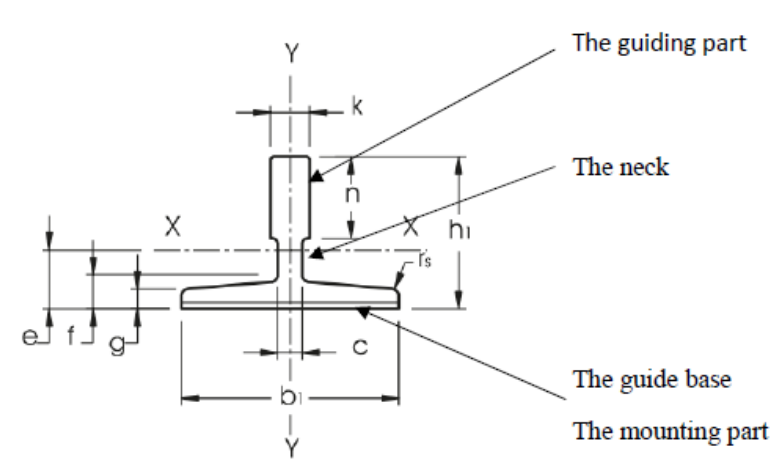

Fig. 1. The lift guide [10]

thor to implement some improvements to CHP 2000 gear design. Finite element method is touched in many publications also in the study [9] in which the author highlights a possibility to use FEM method in designing process of thin-walled elements. Taking into account the possibilities given by the finite element method, the authors in their research study [6] focused on the application of FEM to analyse the loading variability of CHP 2000 type gear and the impact of loading changeability on the braking distance. The numerical analyses results were verified on the test bench with the loading of $8000 \mathrm{~N}$ and $12000 \mathrm{~N}$ applied. The results confirmed the assumptions used for the numerical calculations. In the research study [7] the authors described the pre-tests for the impact of progressive gears geometry on the braking distance length both in changing operation conditions and changing loading. The tests were performed for the progressive gears used in hoisting and hauling equipment. The tests were conducted by use of the free fall
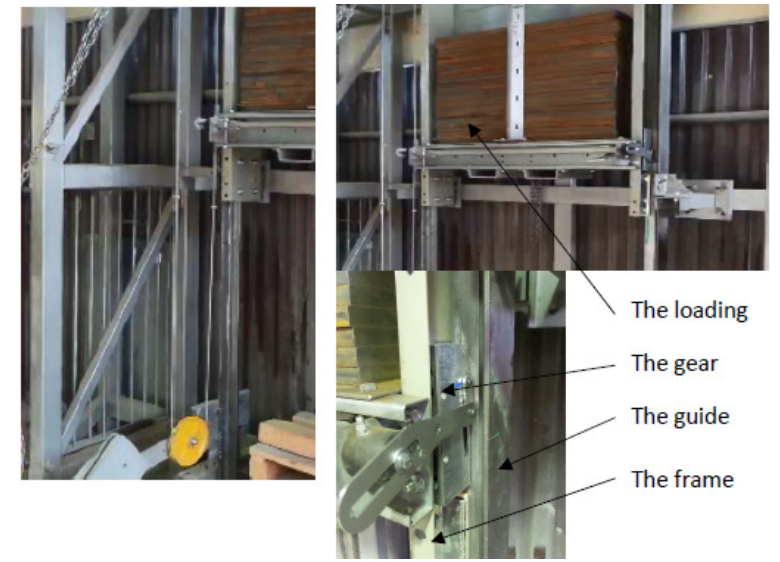

Fig. 2. The test bench [4]

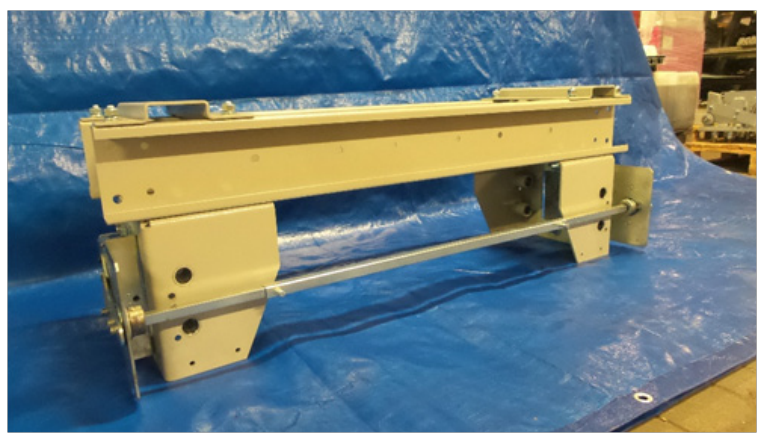

Fig. 3. The test bench frame with the gears installed

method allowing to evaluate the operational reliability of tested gears systems. Tests results obtained in the experiment let the authors collect necessary data to perform further tests on the subject. While analysing the world literature a lack of information in this subjectmatter can be noticed. Thus, it is justifiable to continue the tests in this specific field of study.

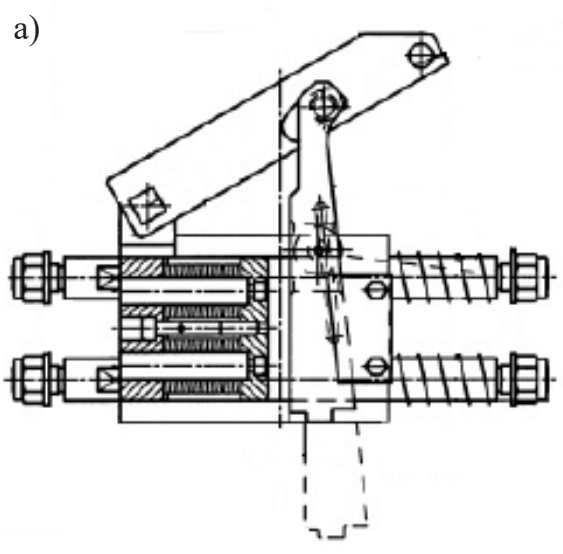

b)

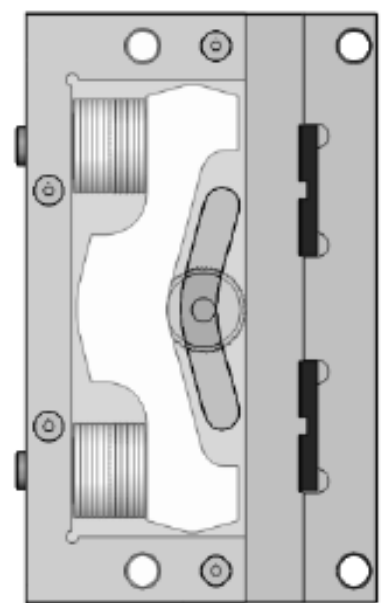

c)

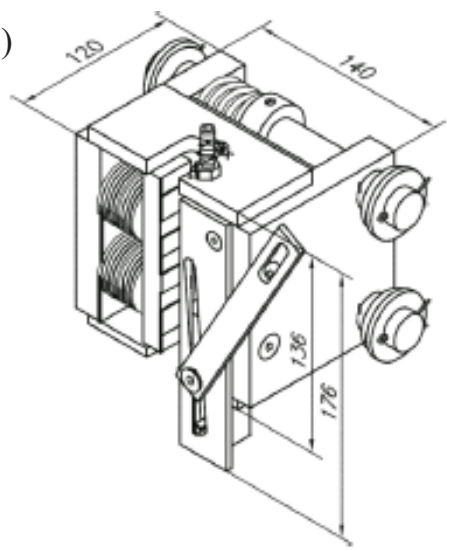

Fig. 4. The tested gears: a) PP16 type, b) CHP 2000 type and c) KB160 [5] 

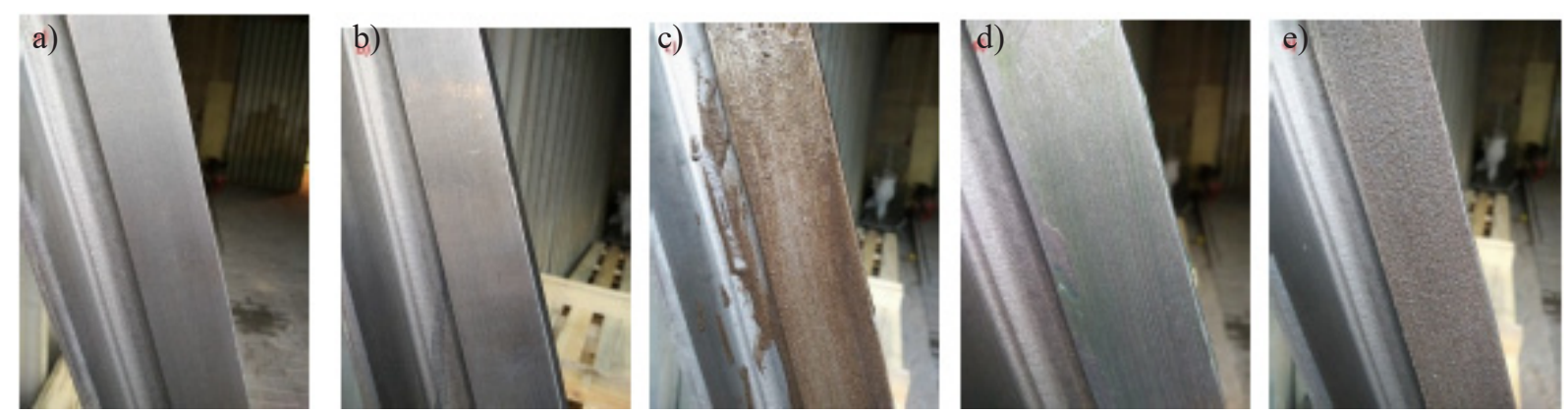

Fig. 5. The guides used in the tests: a) the dry guide $\mathrm{S}, \mathrm{b}$ ) the guide with mineral oil applied $\mathrm{OL}, \mathrm{c}$ ) the guide with a mixture of mineral oil and O50 quartz sand applied, d) the guide with SM solid grease applied,

e) the guide with a mixture of solid grease and S50 quartz sand applied

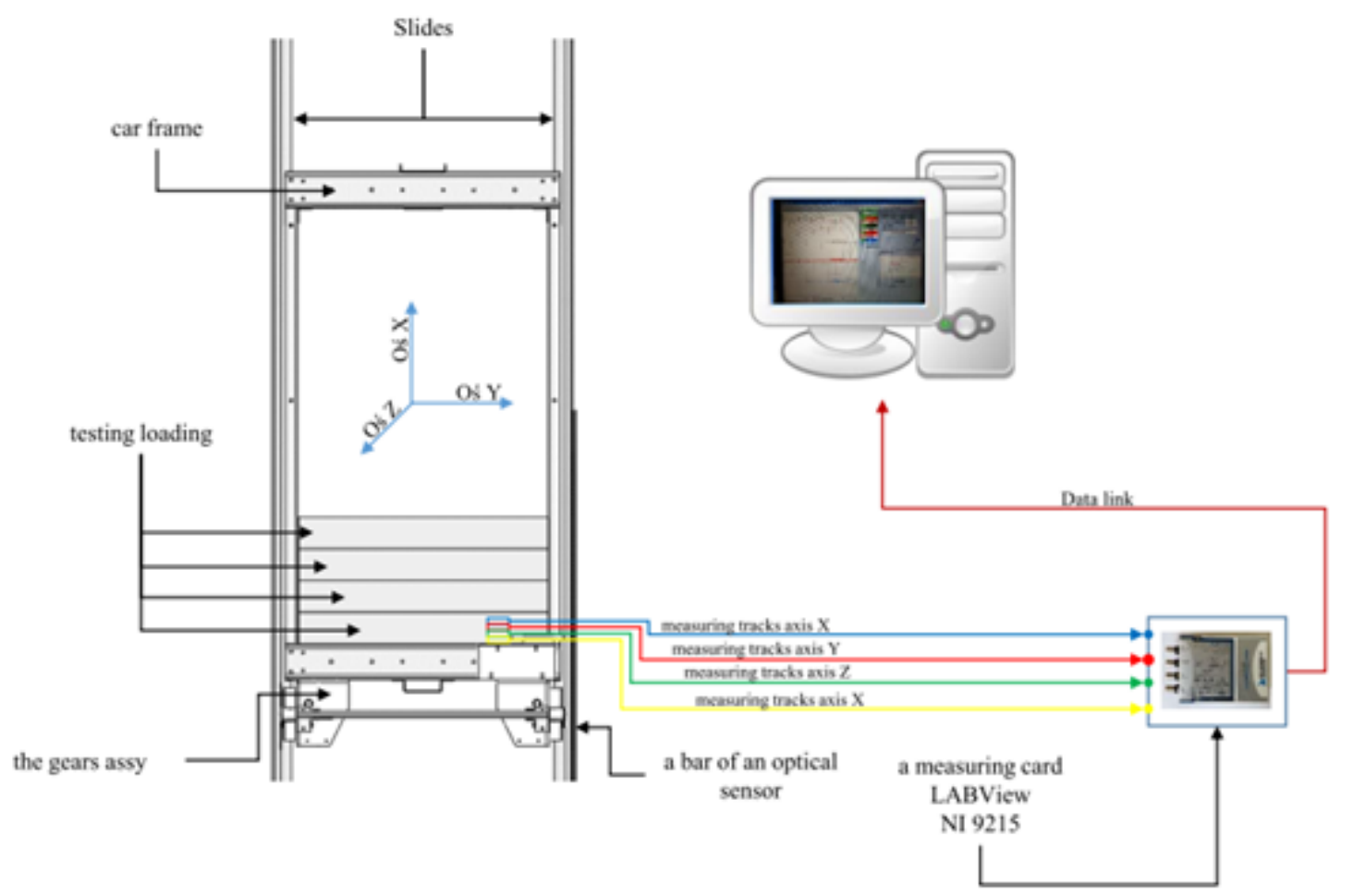

Fig. 6. The test bench scheme used for the experiment [7]

\section{THE TEST BENCH, TESTING METHODOLOGY}

Tests conducted by using the free fall method were performed on the test bench, the scheme of which is presented in Figure 2. The respective types of the gears were mounted in the frame presented in Figure 3. Kinematic schemes of sliding gears: PP16, CHP2000 and KB160 used for the tests are presented in Figure 4.

The Figure 5 presents the guides: the dry one starting from the left side and the guides with lubricating agents applied. The tests aimed at increasing the speed of tested system. The speed increased due to the free fall. The gears were activated with a speed limiter, the speed of which was set at $1.25 \mathrm{~m} / \mathrm{s}$. When the speed set for the speed limiter was exceeded the release of tested systems and in other words the start up of braking process took place. The test bench scheme is presented in Figure 6.

Measuring equipment and software prepared especially for the tests described in this research study were used to measure accelerations and braking distance. All four measuring paths were connected to LABVIEW 9215 measuring card. The card was coupled with PC class computer to record the received data. 


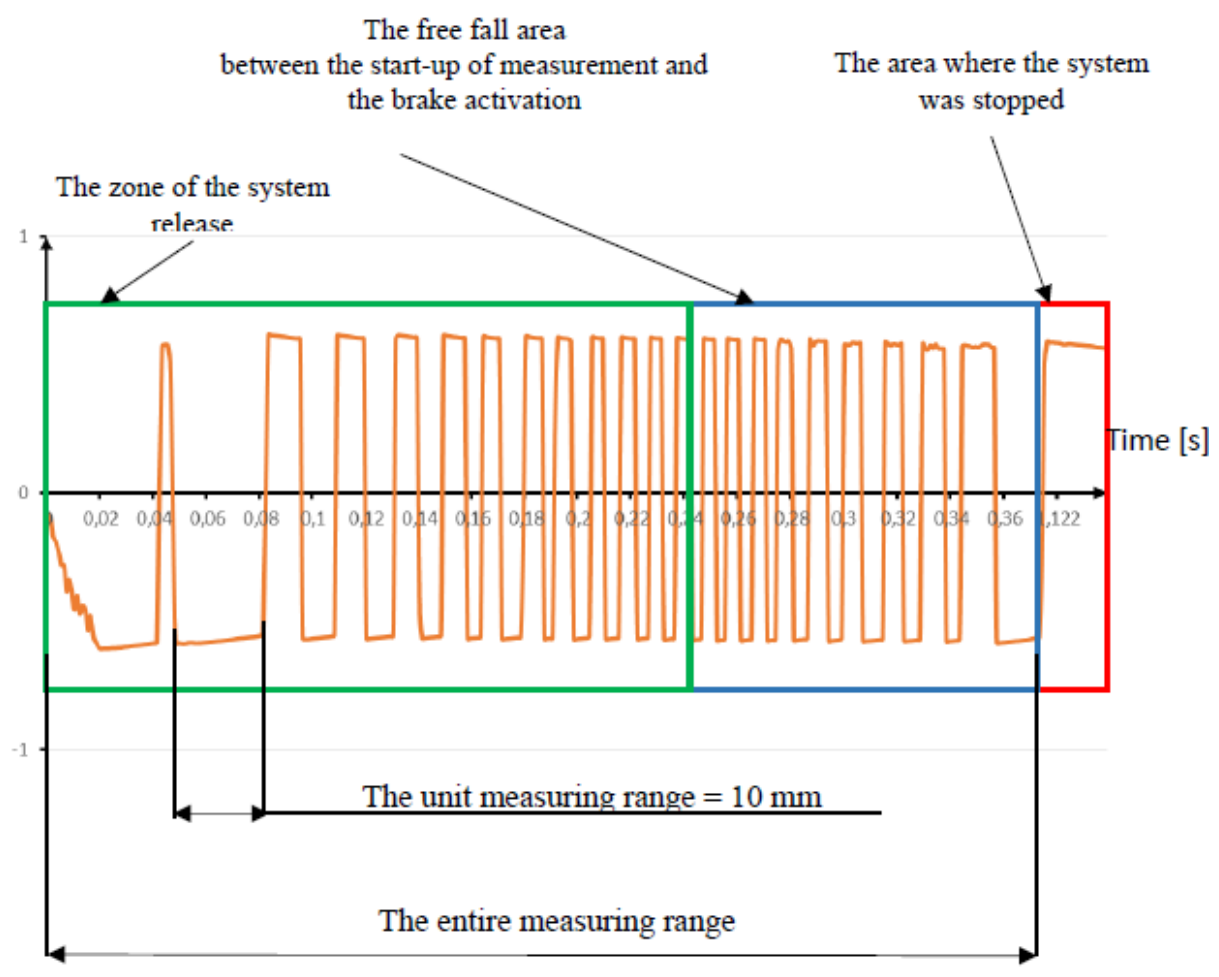

Fig. 7. Stages of tested systems braking process

\section{THE KEY RESULTS OF EXPERIMENTAL} TESTS

Data was recorded at the sampling frequency of $1 \mathrm{kHz}$ and the number of samples in one round was 2000. Due to the experimental tests the time of recording was 2 seconds. Theoretical modal analysis is often based on the numerical grounds which are broadly used to verify dynamics of tested construction. With reference to the above, the following empirical dependence (1) [6] can express an exemplary formula of the mechanical system dynamic movement:

$$
\mathrm{f}(\mathrm{t})=|\mathrm{M}|\{\ddot{\mathrm{u}}\}+|\mathrm{C}|\{\dot{\mathrm{u}}\}+|\mathrm{K}|\{\mathrm{u}\}
$$

where: $\{\ddot{\mathrm{u}}\},\{\dot{\mathrm{u}}\},\{\mathrm{u}\}-$ represent the vectors respectively: acceleration, speed and displacement, $|\mathrm{M}|,|\mathrm{C}|,|\mathrm{K}|$ - represent the matrices respectively: mass, stiffness and dampening.

In the above mentioned cases, it is difficult to describe the analysed aspects using empirical equations due to the complexity of phenomena occurring during the braking process in various operating conditions.

Figure 7 presents an effective recording fragment (braking process) of the free fall distance for tested systems. The total area of the free fall during the tests can be divided into three stages. The

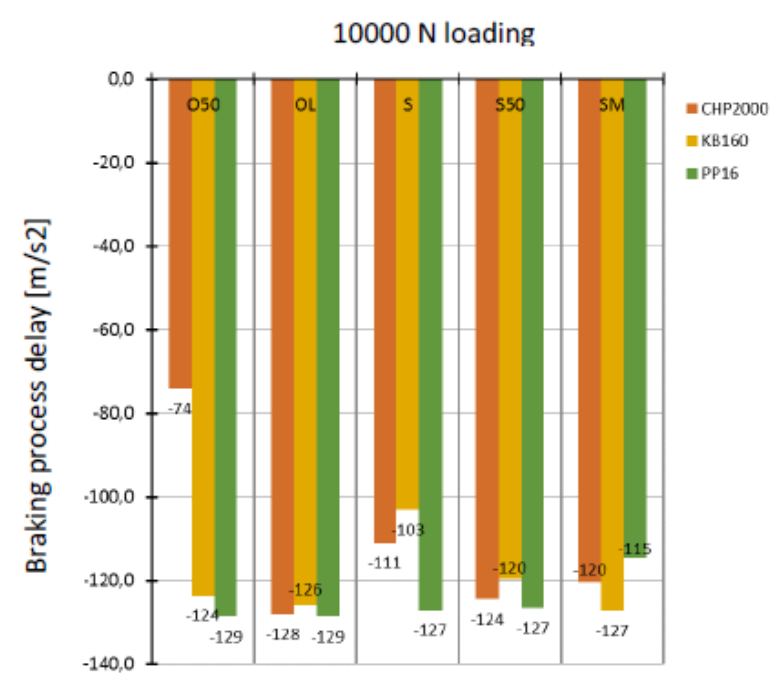

Fig. 8. The values of braking delay of the system tested with $10000 \mathrm{~N}$ loading for CHP2000, KB160, and PP16 gears in different operating conditions

first one (green) is the free fall area starting from the fall initiation up to the gear release. The gear release means that a braking roller has changed its position. The second area (blue) represents the stage from the gear release to its stop. The third one (red) is the stage from the stop of recording to its end. The unit measuring range described on the measuring tape of the optical sensor was $10 \mathrm{~mm}$. The values of braking distance presented 


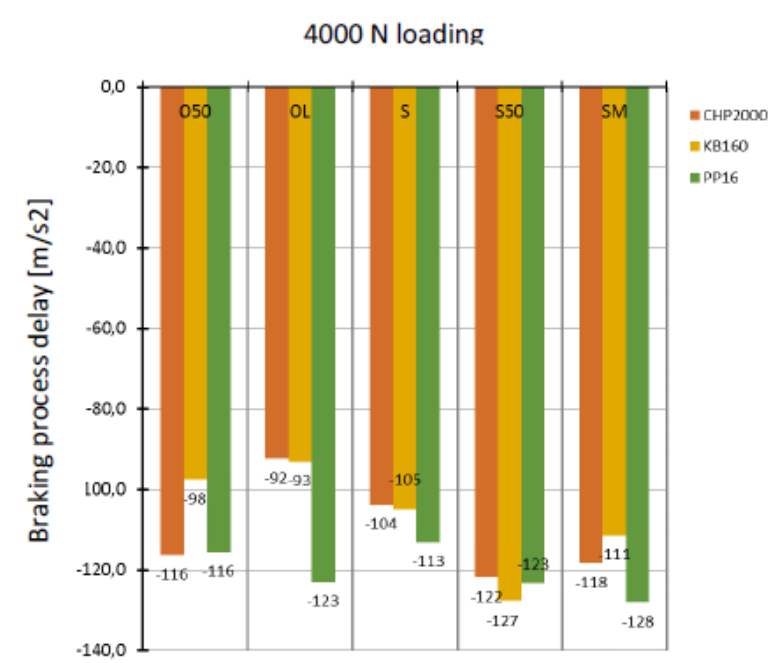

Fig. 9. The values of braking delay of the system tested with $4000 \mathrm{~N}$ loading for CHP2000, KB160 and PP16 gears in different operating conditions

in Figure 7 cut through a horizontal axis. It was caused by the read out of the optical sensor measuring bar. A positive value was described with light colour on the bar and for the negative value a dark colour was used. Thus, the braking distance was recorded by the read-out of changing colouring placed on the sensor bar. It was the bar with $10 \mathrm{~mm}$ scale.

Results for maximum values of delays received in the experiment conducted with the gears of CHP2000, KB160 and PP16 type in changing operating conditions, described above, are presented in Figures 8, 9 and 10.

\section{STATISTICAL ANALYSIS OF THE RESULTS}

Examples of descriptive statistics for measurements conducted with $6000 \mathrm{~N}$ loading are presented in Figures 11-12. The statistics of skewness and kurtosis were analysed. In the analysed cases the skewness is a measure of distributions deviation from symmetry. The empirical dependence (2) [11] describes the mathematical interpretation of skewness.

$$
S K E=\frac{x \cdot\left(x_{i}-\bar{x}\right)^{3}}{(n-1) \cdot(n-2) \cdot s^{3}}
$$

where: SKE - the skewness coefficient, $\mathrm{n}$ - the number of observations, $x_{i}-$ the result of the successive observation, $\overline{\mathrm{x}}-$ the average, $\mathrm{s}-$ the standard deviation

In the analysed cases, kurtosis measures the distribution ,pointedness”. If the value of kurtosis

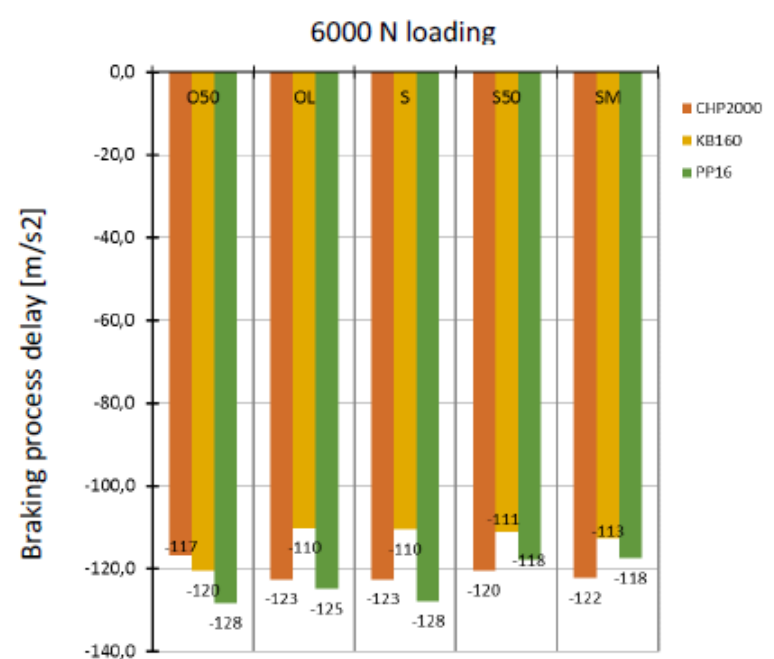

Fig. 10. The values of braking delay of the system tested with $6000 \mathrm{~N}$ loading for CHP2000, KB160 and PP16 gears in different operating conditions

is visibly different to zero then the distribution is either more flat or more pointed than the normal distribution. The empirical dependence (3) [11] describes the mathematical interpretation of kurtosis.

$$
\begin{gathered}
K=\frac{n(n+1)}{(n-1)(n-2)(n-3)} \sum_{i=1}^{N}\left(\frac{x_{i}-\bar{x}}{s}\right)^{4}- \\
-\frac{3(n-1)^{2}}{(n-2)(n-3)}
\end{gathered}
$$

where: $\mathrm{K}$ - kurtosis, $\mathrm{n}$ - the number of observations, $x_{i}-$ the result of the successive observation, $\overline{\mathrm{x}}-$ the average, $\mathrm{s}$ - the standard deviation

Figure 11 presents the examples of kurtosis coefficients with the values higher than zero. Especially it refers to CHP2000 gears for which the values were in a range from 15 to 22 . For KB160 and PP16 gears the kurtosis reached the values in a range from 5 to 10 . Basing on that, the conclusion can be drawn that the average values of delays during the experiment for CHP2000 gears are lower than for the gears of KB160 and PP16 type. Generally, it is connected with the gears construction where the cam is the main braking element and not the roller. Thus, the distribution takes the form of leptokurtosis.

Analysing a diagram presented in Figure 12 it can be noticed that the skewness takes the minus values. In the analysed cases, the braking process and the carrying frame built as an assembled construction have the impact on the left side distribution of skewness. Consequently, during the experiment conducted by use of the free fall 


\section{$6000 \mathrm{~N}$ loading}

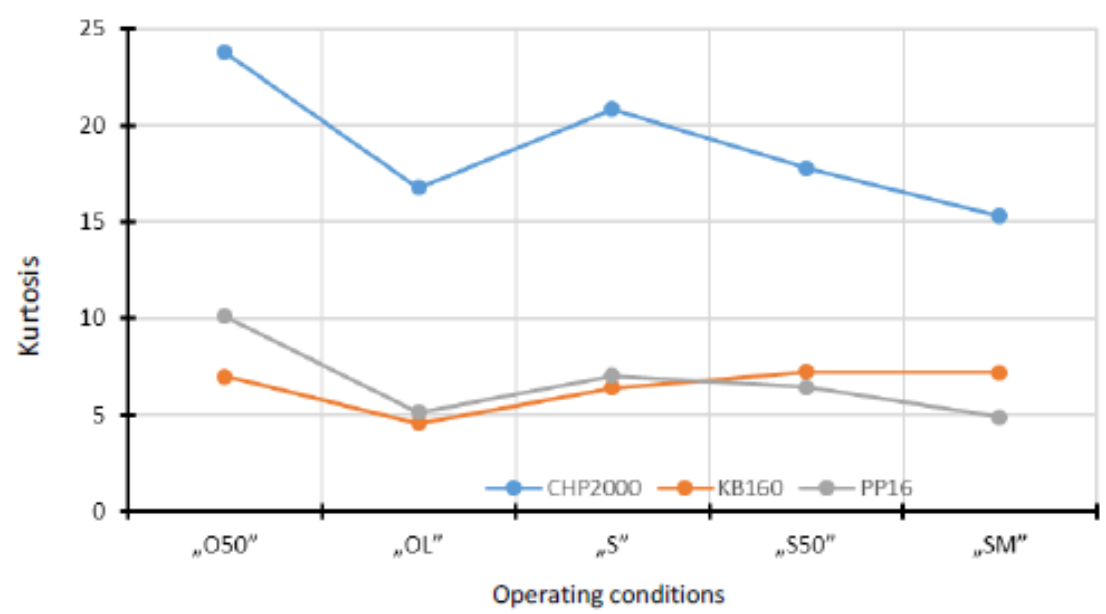

Fig. 11. The kurtosis coefficient for the gears tested with $6000 \mathrm{~N}$ loading in different operating conditions

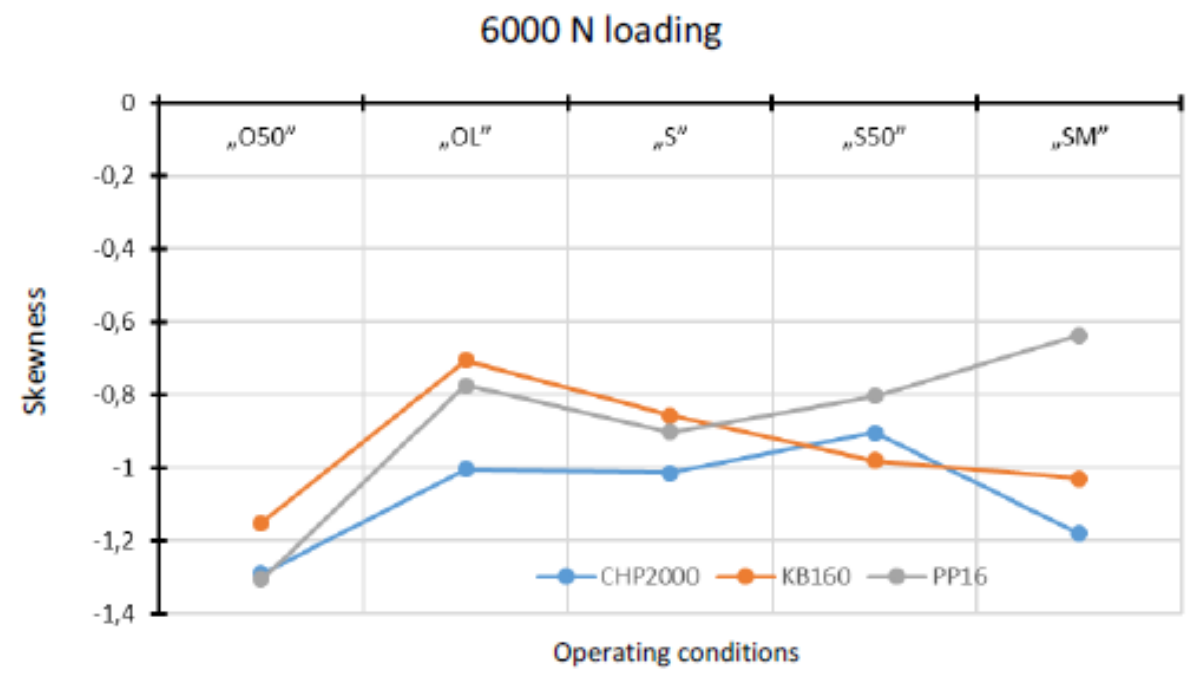

Fig. 12. The skewness coefficient for the gears tested with $6000 \mathrm{~N}$ loading in different operating conditions

method, in the working condition of the gears the carrying frame was subject to loadings connected with the braking process dynamics. In effect, the vibrations in the frame construction were damped in the final stage of braking process.

\section{CONCLUSIONS}

Complexity of phenomena accompanying the braking process, in other words the condition of the guides cleanliness or the quality of applied grease do not always allow to identify the process to full extent. Then, a trial is made to identify a physical model by observation using simulation and laboratory tests [7]. Analysing the values of delays received in the experiment, the impact of the guides lubrication and contamination caused by greasing agents, their significant influence on the braking distance and in consequence on the delay value can be noticed. For the lift gears a steadiness of braking process is an indispensable condition to avoid some permanent damage of the lift carrying construction.

Basing on the received diagrams of delays for different loadings it can be noticed that PP16 gears are the least susceptible to changing conditions of the guides cleanliness. Probably, it is connected with a blocking mechanism construction. The mechanism has a bigger contact surface on the both sides of the guide. It is also linked with the longest reached braking distance caused by the lowest pressure on the blocking element guide. CHP2000 gears represent completely dif- 
ferent construction. They possess a knurled roller as a blocking element. Due to this construction the pressure generated during the braking process is the highest and in consequence the received values of delays and the length of braking distance are the shortest.

For the guides in dry condition (S) the gears of CHP 2000 type achieved a value of delay in the range of $104 \mathrm{~mm} / \mathrm{s}^{2}$. In comparison, the gears of KB160 and PP16 type obtained the results: 125 and $128 \mathrm{~mm} / \mathrm{s}^{2}$ respectively. For the guides lubricated with oil the following delay results were recorded: 98,104 and $129 \mathrm{~mm} / \mathrm{s}^{2}$. Whereas, for the guides lubricated with a mixture of oil and quartz sand the values of delay were the following: 119 , 128 and $129 \mathrm{~mm} / \mathrm{s}^{2}$. For the guides lubricated with grease and a mixture of grease, the lowest values of delay were reached for KB160 type gears due to their kinematics and different construction of susceptible elements (used in the gears) responsible for the braking process. Alike similarities of delay values were obtained for $4000 \mathrm{~N}$ and 10000 $\mathrm{N}$ loadings. Analysing the obtained values of delay it can be stated that CHP2000 type gears demonstrate a greater sensitivity to changing working conditions than the two remaining types of the gears subject to experimental tests.

Moreover, it can be noticed that in majority of analysed cases the contamination of the guides with quartz sand reduced the braking distance. As a result of that the friction coefficient was increased by adding silica (kinematic friction of a steel roller - it is approximately 0.09 for steel, for the steel roller in a contact with concrete (material containing silica) 0.3 ). It was caused by the increase of friction coefficient by adding silica

The achieved results confirm the regularity of proposed gears construction and provide the grounds to continue further research studies to reduce the impact of environmental conditions (condition of the guides) on effectiveness of braking distance.

\section{REFERENCES}

1. Gardyński L., Lonkwic P. ,,Testing Polymer Rollers Memory in the Context of Passenger Lift Car Comfort", Journal of Vibroengineering vol. 1 (2014), 16, 225 - 230.

2. Klepka T., Dębski H., Rydarowski H. Characteristic of high-density polyethylene and its properties simulation with use of finite element method. Polimery 54 (9), 2009, 668-672.

3. Kwaśniewski J. : „Passenger and cargo elevators the construction and operating conditions", AGH University of Science and Technology Press, Cracow 2006.

4. Lonkwic P, Różyło P, Dębski H. Numerical and experimental analysis of the progressive gear body with the use of finite-element method. Maintenance and Reliability 17(4), 2015, 542-548, http:// dx.doi.org/10.17531/ein.2015.4.9.

5. Lonkwic P. Influence of friction drive lift gears construction on the length of braking distance. Chinese Journal of Mechanical Engineering 28 (2), 2015, 363-368.

6. Lonkwic P., Różyło P. “Theoretical and experimental analysis of loading impact from the progressive gear on the lift braking distance with the use of the free fall method", Advances in Science and Technology Research Journal, vol. 10 (30) , 103-109, 2016, DOI: $10.12913 / 22998624 / 62628$.

7. Lonkwic P., Szydło K., Molski Sz. "The impact of progressive gear geometry on the braking distance length under changeable operating conditions", Advances in Science and Technology Research Journal vol. 1 (2016), 29, pages 161 - 167, DOI: $10.12913 / 22998624 / 61948$.

8. The Polish Standard PN EN 81-1 Safety regulations on the elevators construction and installation. Part 1. Electrical elevators 2002.

9. Różyło P.: Optimization of I-section profile design by the finite element method;. Advances in Science and Technology Research Journal, 2016, vol. 10, no. 29 , p.52-56.

10. Website: www.monteferro.it.

11. Website: www.statsoft.pl. 